STUDI

FRANCESI

\section{Studi Francesi}

Rivista quadrimestrale fondata da Franco Simone

194 (LXV | II) | 2021

Baudelaire et son cénacle

\title{
JULES MICHELET, Histoire de la Révolution française
}

\section{Lise Sabourin}

\section{(2) OpenEdition \\ Journals}

\section{Édition électronique}

URL : https://journals.openedition.org/studifrancesi/45214

DOI : $10.4000 /$ studifrancesi.45214

ISSN : 2421-5856

\section{Éditeur}

Rosenberg \& Sellier

\section{Édition imprimée}

Date de publication : 1 août 2021

Pagination : 382-383

ISSN : 0039-2944

\section{Référence électronique}

Lise Sabourin, « JULES Michelet, Histoire de la Révolution française », Studi Francesi [En ligne], 194 (LXV |

II) | 2021, mis en ligne le 01 septembre 2021, consulté le 15 octobre 2022. URL : http://

journals.openedition.org/studifrancesi/45214; DOI : https://doi.org/10.4000/studifrancesi.45214

Ce document a été généré automatiquement le 15 octobre 2022.

\section{(c) (†)}

Creative Commons - Attribution - Pas d'Utilisation Commerciale - Pas de Modification 4.0 International - CC BY-NC-ND 4.0

https://creativecommons.org/licenses/by-nc-nd/4.0/ 


\title{
JULES MICHELET, Histoire de la Révolution française
}

\author{
Lise Sabourin
}

\section{RÉFÉRENCE}

JULES MICHELET, Histoire de la Révolution française, édition publiée sous la direction de P. Petitier, avec la collaboration de M. Biard, Ph. Bourdin, J.-Cl. Caron, A. Déruelle, H. Leuwers, F. Lotterie, D. Pety, J.-M. Roulin, C. Rétat, C. Saminadayar-Perrin, J. Wulf, Gallimard, 2019, «Bibliothèque de la Pléiade», 2 tomes, 1556 pp.

1 Cette édition dans la «Bibliothèque de la Pléiade», contrairement au principe de cette collection généralement appuyée sur la dernière parue du vivant de l'auteur, se fonde sur l'édition originale de l'Histoire de la Révolution française telle que la publia Michelet en 7 volumes chez Chamerot. Ce choix éditorial permet de souligner la scansion liée à l'actualité sociale et politique qui accompagne la rédaction. Les notices, ainsi que l'introduction générale (pp. I-LIV), démontrent combien Michelet évolue dans sa pensée de la chute de la Monarchie de Juillet à l'avènement du Second Empire. C'est un professeur reconnu, jouissant de sa liberté au Collège de France, un directeur des Archives nationales, qui commence cette œuvre en 1847; c'est un enseignant interdit puis destitué, un fonctionnaire démissionnaire par refus de serment, un exilé intérieur provincial qui la termine en 1853. Entretemps a surgi l'espoir de février 48, puis l'effondrement sanglant de juin, l'élection du prince-président, le coup d'État bonapartiste et le retour de la censure de 1803 ... Les survivants de l'époque révolutionnaire publient désormais surtout des témoignages avant d'être emportés par la succession naturelle des générations.

2 L'Histoire de la Révolution française est au cœur de l'œuvre de Michelet, fondant le diptyque entre son Histoire de France (des Gaulois et du Moyen Âge à l'Ancien Régime) et l'Histoire du XIX siècle (en fait de 1794 à 1815) qui explique l'inaboutissement du rêve révolutionnaire. Les événements de 1848 ont conforté sa conviction intime que le 
peuple fait l'histoire, mais se voit souvent dépossédé par les personnalités qui émergent de ses élans. En cela Michelet diverge de ses contemporains, qui, même républicains, tels Louis Blanc, Esquiros ou Lamartine, donnent plus de place aux individualités d'exception dans l'avancement des institutions; a fortiori des néo-jacobins de la Restauration, des libéraux Mignet et Thiers, et bien évidemment des réactionnaires Burke et Maistre.

Comme le souligne la préface qui conçoit le mouvement de l'histoire comme un combat entre la Grâce et la Justice, Michelet considère l'époque contemporaine comme l'ère de l'esprit, enfin dévoilé en apocalypse d'un monde nouveau régénérant humainement l'ordre divin de la Genèse fondé sur le péché originel. Pour lui, la Révolution est une révélation qui fait succéder au chaos l'espérance d'un futur terrestre fraternel. Il cherche aussi, non seulement à brosser le tableau des faits, mais surtout à expliquer leur déroulement. C'est pourquoi il met en valeur les moments qui lui paraissent manifester l'action de la foule, unie et sans meneur pense-t-il, face au blocage des Assemblées formelles: le 14 juillet, de la Bastille comme de la Fédération (qui n'était pas encore fête nationale avant 1880), les 5 et 6 octobre, le 10 août sont pour lui les sommets de cette nation en marche vers le XIX ${ }^{e}$ siècle, que le rétrécissement autour d'instances juridiques ou de personnages agissants a mené à un retour de l'inquisition et de l'exclusion jusqu'au 9 thermidor. La chute de Robespierre marque pour lui la fin de la Révolution, minée par la division, et explique la lenteur du processus ultérieur d'émancipation des peuples dont 1848 vient encore de marquer l'ambition mais aussi l'inaboutissement.

4 Le «volcan fécond» de ces cinq années révolutionnaires constitue un être en soi pour Michelet qui s'attache à en montrer l'apport pour le futur, mais aussi les causes d'inaccomplissement. Loin de s'en tenir à la pression des ennemis extérieurs (l'Angleterre notamment), il en trouve aussi les responsabilités internes. La Convention n'a pas assez pensé à l'éducation du peuple, notamment des femmes; le culte de l'Être suprême n'a pas réussi à donner une dimension religieuse nécessaire au mouvement collectif, ressoudant par sa politique de persécution une Église catholique pourtant défaillante sous l'Ancien Régime; après l'enthousiasme des volontaires de 1792, la Terreur a restreint le pouvoir au Comité de salut public, ce qui a fait de Robespierre un roi républicain, tout en signant l'abandon du véritable droit: son élimination a alors suffi à ravaler le régime à la résurgence des intérêts individuels.

5 Cette lecture très engagée des faits, tout en restant un paradigme pour les historiens, a pu être dépassée par des travaux ultérieurs, mais elle reste majeure par sa force de conception et d'écriture, qui excelle par son rendu visuel, son intériorisation spectacle des événements. Ce que marque d'ailleurs sa référence, souvent discrète, mais intime, pour les écrivains (tels, parmi ses contemporains, Flaubert et Dumas, et, plus tard, Yourcenar, Gide et Valéry). L'Histoire de la Révolution française de Michelet est un réservoir d'intuitions, marque une attention au symbolique, une sensibilité et une intelligence du monde concret, un sens aigu des conjonctures si puissant que personne ne peut échapper à la force de ses tableaux flamboyants, à la ductilité de son style admiré de Proust comme de Claude Simon, à l'entrelacement sans pareil de la pensée logique et de l'imaginaire dans sa résurrection du passé.

6 Si l'édition originale fut un échec financier, dû entre autres au contexte restrictif de vente en 1848, la seconde édition chez le belge Lacroix en 1868-69 connut un beau succès: elle donna l'occasion à l'auteur de remanier quelque peu son texte, notamment 
face aux critiques de Louis Blanc, et de souligner la structure binaire de l'œuvre. Mais la consécration vint surtout sous la Troisième République qui soutint et diffusa l'édition de 1889, et forgea la mentalité de ses citoyens en faisant de ses morceaux choisis un véritable manuel d'éducation populaire. 